\title{
Thinking food like an East European: a critical reflection on the framing of food systems
}

Petr Jehličkaab, Miḳelis Grīviṇšc ${ }^{c}$ Oane Visser ${ }^{d}$ and Bálint Balázs ${ }^{e}$

a Department of Geography, The Open University, Milton Keynes, UK

b Department of Geography, Faculty of Science, Masaryk University, Brno, Czechia

c Baltic Studies Centre, Riga, Latvia

d International Institute of Social Studies (ISS) of Erasmus University Rotterdam, The Hague, the Netherlands

e Environmental Social Science Research Group, Budapest, Hungary

\section{AUTHOR VERSION}

Please cite the original journal version:

Petr Jehlička, Miḳelis Grīvin̦š, Oane Visser and Bálint Balázs, (2020) Thinking food like an East European: a critical reflection on the framing of food systems. Journal of Rural Studies, vol. 76, May 2020, p. 286-295.

\section{Highlights}

- Food practices which are marginal in the West are widely encountered in Eastern Europe.

- These practices located at the intersection of the formal market and non-market economies.

- They are based on the entangling of binaries considered to stand in opposition.

- This makes Eastern Europe a source of innovative and critical thinking about AFNs.

\begin{abstract}
Drawing on our long-term research experiences, in this deliberately provocative but also reflexive paper we argue that international food and agriculture studies are a research area that would particularly benefit from insights obtained from research conducted in the world's peripheries-in this case, specifically from insights on East European food systems. Instead of seeing them as textbook case studies of undeveloped, traditional and hence uninspiring systems, we propose to study them from the East European perspective. This enables us to move away from an unidirectional development path and to acknowledge the diversity, resilience and unintended but real sustainability of the melange of East European formal and informal food systems. Such endeavour reveals food that
\end{abstract}


is not locked in food chains, food initiatives or diets. It recognises meanings that go beyond the conventional food system terminology and are rooted in surrounding contexts. Evidence from Eastern Europe reveals a rich diversity of food practices challenging normative assumptions and neatly structured explanatory models underlying Western food system scholarship.

\section{Introduction: The agro-food system and the politics of knowledge production}

This paper seeks to open a new line of enquiry in the academic debates on the agro-food system's transformation by proposing to include in these discussions insights from a region rarely considered as a source of new academic knowledge-the European East. While mindful of the need to avoid essentialisation of the European East and West and instead to acknowledge the links, connections and relational dynamics between them (Blazek and Šuška, 2017), we are, nevertheless, aware of the established hierarchy of social science claims: while the West European (and North American) context is perceived as a source of universally valid knowledge claims, Eastern Europe is expected to be a mere recipient and testing ground for concepts and research agendas developed in the West (Kuus, 2004). ${ }^{1}$ In the last one and a half decade or so, the global South has increasingly been thought of as part and source of global knowledge communications and claims (Connell, 2007; Roy, 2011 and 2016; Comaroff and Comaroff, 2012). In contrast, in the late 2010s, Eastern Europe, located in the 'interstitial position between North and South', continues to be excluded from the circuits of cosmopolitan knowledge production and communication: 'In the push for decolonial knowledge and theorising from the South, the East gets no mention ... it simply is not part of this project' (Müller, 2018). According to Müller (2018, p. 4), Eastness is first and foremost 'a liminal condition of in-betweenness - not-quite North, not-quite South', as the East is too powerful to be periphery, but too weak to be the centre.

Despite this disadvantageous framing of Eastern Europe affecting its potential as a source of general knowledge, we believe that increasing risks to the world food system require of researchers to search for novel impulses in all social contexts. Eastern Europe is an excellent case in point and in this paper we argue that its agro-food systems harbour important, yet often overlooked, opportunities for innovation, creativity and imagination for scholarly efforts to rethink the agro-food system. Thus, there is an increasingly urgent case for overcoming this hierarchical relationship and for greater equality between 'Western' and 'Eastern' knowledge. Our understanding of this new line of enquiry evolved out of our long-term engaged scholarship with food provisioning, foraging, small-scale farming and seed networks. Most of us gained our formative experiences in formerly state-socialist East European countries and later worked with green civic organisations or gardening groups. In these claims we are motivated by growing calls in several social science disciplines to put Eastern Europe back on the map of knowledge production (Müller, 2018) and to 'decentre the West' by bringing in general debates and theorisations from 'peripheral' and 'marginal' spaces.

Inspired by Jean and John Comaroff's (2012) thesis about the global North 'catching up' with the global South, Martin Müller (2019) proposed theorisations of Western topics, such as US nationalism and British populism, from places in the 'global East', including Russia and Hungary. ${ }^{2}$ Regardless of how tempting this proposition is, this paper does not intend to go as far as theorising the transformation of Dutch or French agriculture and food supply chains from, say, Latvia or Hungary. Instead, we wish to advance a more modest but ultimately a more productive goal-to underline the potential East 
European food practices have to inform the direction of more general discussions on the agro-food system's development.

In this article we argue that international food and agriculture studies are a research area that would particularly benefit from insights from the European East. We do so by highlighting three illustrative cases selected from our previous work. The paper argues that we should stop viewing agro-food practices common to East European food systems as mere case studies or data for Western theory or textbook examples of underdevelopment and tradition. In other words, as uninspiring relicts corresponding with less advanced, past variants of the Western agro-food system. What is needed instead is to move away from a unidirectional development path portraying the development in the European East as simply delayed adoption of Western innovations and to acknowledge the diversity of configurations and the real, even if unintended, sustainability and hidden resilience of the melange of East European formal and informal food systems.

At this point we need to make clear, that while infrastructural disadvantages ('extra-scientific' factors such as funding, English-language proficiency, access to literature and the subsequent inability to submit their research to high-profile international journals) of many East European researchers relative to their Western counterparts might play some role behind the limited drive for East European agro-food scholarship as a source of inspiring theorisations, the key problem lies elsewhere. For it is not the researchers' institutional background but the region (i.e. Eastern Europe) in which they conduct their investigation, which determines how their research resonates, is cited, has influence and thus is considered as a potential source of theorisation by the international academic community. What matters more than extra-scientific disadvantages are 'intra-scientific' factors - the disadvantages scholars working on topics from peripheries such as Eastern Europe face in attempts to produce internationally accepted theory. Whether these scholars are based in Eastern Europe or in the West makes less of a difference - in terms of whether their research is picked up by others - than the fact they produce knowledge on Eastern Europe. While it is difficult to provide a systematic evidence, based on our experience we are confident to claim that knowledge on East European agro-food alternatives that is published in international (i.e. Western) high-calibre journals and produced by Western academics who are based in Western institutions tend not to 'travel' in the sense of influencing and shaping general debates, let alone setting research agendas ${ }^{3}$.

To support this claim we selected four post-2000 influential (at least with 10 citations) articles on East European informal food practices that that we were familiar with from our work and that were authored by Western academics based in Western institutions and published in reputable Western journals: Acheson's (2007) article on Slovakia, Round et al's (2010) article on Ukraine, Smith and Rochovská's (2007) article on Slovakia and Zavisca's (2003) article on Russia. Then we looked at articles that cited these articles in terms of the geographical context (the world's region) in which the research in citing articles was conducted. Invariably, the original articles were primarily cited by researchers (whether Western of East European) who work on Eastern Europe. Very rarely and in some cases not at all the original articles were cited by authors who research non-East European topics as the percentage of citing articles on Eastern Europe ranges from 72 (Smith and Rochovská, 2007) to 100 per cent (Acheson (2007). This suggests that East European knowledge 'does not travel'; in other words is rarely or not at all picked up by researchers working on other regions. ${ }^{4}$

The article does not deny the achievements or benefits of engagement with Western knowledge for analyses of the food systems in Eastern Europe. Instead, it calls for greater academic equality in terms of writing styles, division of labour, openness and receptivity to the possibility of theorising from and 
with the European East. It also recognises that to find solutions to the global agro-food challenges it should be ensured that information and ideas flow in all directions, not just from self-proclaimed theory-generating centres to the areas on which the centre bestowed periphery status.

In the next section we discuss where and by whom the debate about the common problems of the agro-food system and its proposed alternatives is advanced. Much of this debate originates in the (European) West. We need to add at this point that trends such as the promotion of large-scale farming at the expense of smallholders was not a result of only Western dominance in policy formulation circles but also of many domestic East European politicians' preferences driven by the imperatives of modernisation. Similar trends have been reflected in academia, where Western dominance in rural studies, has not only been the result of the West actively prolongating its preexisting dominance, but also of many East European scholars' adoption of what they considered 'proper', i.e. Western models. The same development could for a long time be observed in relation to scholarship on East European alternatives (farmers' markets, organic food, community supported

agriculture) to the conventional agro-food system. This has resulted in certain tendencies (seeing food through the lens of formal institutions; assuming that food flows relate predominantly to the realm of the formal market economy; perceiving food as a self-contained field of inquiry) in terms of what tends to be considered key attributes of agro-food systems. Scholarly attempts (by both East European and Western researchers) to reverse this 'Westernisation' perspective and to seek insights from East European research on agro-food systems as a source of theory generating inspiration worth considering by academics working outside the region are a very recent rarity. ${ }^{5}$

Section 3 discusses the tensions arising from attempts to represent the evidence from Eastern Europe by deploying the terminology and concepts developed in West European contexts. To illustrate this point, three examples of agro-food practices are then presented in Section 4. These three cases shed light on some often overlooked yet inspiring aspects of East European agro-food systems. The practices outlined in these three cases cannot be easily reconciled with categories and conceptualisations used in alternative food scholarship that have been developed in Western contexts. This is one of the reasons why these East European practices have been overlooked or their importance downgraded in much of the contemporary academic literature. The first example shows the symbiotic relationship between large farms and subsidiary household plots. The second example highlights the importance of household food production and sharing in the food system. Finally, the third example presents foraging as a viable source of nutrition and a way to retain ties between local communities and their environments. The article concludes in the Discussion and Conclusion sections by suggesting that in searching for responses to the current food system's problems agro-food debates should start engaging with evidence and insights originating in the European East.

\section{The industrial agro-food system and its dominant alternative}

One of the foremost Western political-economic achievements is the creation of the industrial agrofood system as a standalone operational field-a technologically and economically sophisticated supply management system detached from the general public's experiences (Bruinsma, 2003). This system is centred on efficiency, technological innovation, increased marketisation, corporatisation and globalisation. This highly technologised model of the agro-food system has been exported and adopted worldwide including, for example, as the Green Revolution between the 1960s and 1980s in 
the global South and as post-1989 marketisation and privatisation of East European agro-food systems. It has had a profound influence on how policymakers and academics think about agriculture and food, bestowing on it the status of the mainstream model to which the rest of the world aspires and against which other possible models (so-called 'alternatives') are evaluated.

In light of the discoveries of soil, biodiversity and climate deterioration (Garnett, 2011) resulting from the adoption of industrial agriculture and its accelerated intensification in many parts of the world, however, there has been a growing anxiety about the global agro-food system's ecological fragility (Blandford and Hassapoyannes, 2018; Gruère et al., 2018). This has been compounded by the structural challenges associated with the production and consumption sides of agro-food systems and with changes in the context in which supply chains are embedded. Food production is increasingly characterised by corporate control of the food system, growing social and economic inequality, financialisation, and land grabbing (Bruinsma, 2003; Clapp, 2016). On the consumption side, the health effects caused by the diffusion of the affluent diet, such as growing rates of obesity and degenerative diseases, have been the major cause of concern in the last several decades. Meanwhile, there has also been a sense of unease regarding the effects of some concomitant processes on agro-food systems, such as the world's increasingly urbanised population's disconnect from the processes of food production. As a result, there is an urgently felt need to develop an alternative to the dominant agrofood system. In the last two decades, these discussions have relied on notions like alternative food networks (AFNs), food relocalisation, urban and peri-urban agriculture, multifunctional agriculture, and food certification schemes. These concepts have become a standard response to calls to reform the food system along the lines of reconnecting food production with its socio-ecological contexts.

While alternative food scholarship has been an exceptionally productive research field since 2000, more recently these debates, increasingly critical of AFNs' capacity to transform the food system (e.g. Tregear, 2011; Sonnino and Griggs-Trevarthen, 2013; Grivins et al., 2017), have been conspicuously unreflective in relation to two important and interrelated questions. The first question concerns the provenance of academic concepts and theories in alternative agro-food scholarship (i.e. the academic context with which their origin is associated). The second question concerns the kind of socioeconomic reality this body of knowledge reproduces.

As to the first question, a search of the Scopus database for post-2000 articles including the term 'alternative food networks' reveals that research institutions located in Western Europe heavily dominated research on this topic. ${ }^{6}$ Institutions that dominate the list of research institutions with the most robust publication records on this topic are from the Netherlands, France and the UK. This list does not include any research body located in Eastern Europe. At the individual level, only two researchers from Eastern Europe have managed to enter a similar list of the most published researchers (this list is dominated by researchers based in UK institutions). These findings also apply to authors who engage with other concepts that are typically used in analyses of agro-food alternatives (such as 'local food', 'small-scale farming', 'multi-functional agriculture' and 'food sharing'). Similar observations can also be drawn from the geographical distribution of funding allocated to research on these topics. For example, in 2019 the database of the European Commission's Community Research and Development Information Service included only a handful of studies which were prepared and/or conducted with the involvement of research partners from Eastern Europe. ${ }^{7}$ Thus, these debates are advanced mostly by actors with institutional backgrounds in the specific social context of West European, affluent and highly urbanised societies, which are rather 
dissimilar to the range of non-Western contexts around the world. In other words, research on alternative approaches to the dominant agro-food system is primarily produced in a 'minority' world.

This leads to the second question that the alternative food research community rarely reflects upon what kind of reality do these alternatives promote and reproduce? For the most part, the answer has been the Western context of the ascendant neoliberal policy and economy of the late 1990s and 2000s, which prioritised alternatives to the food system and its transformations based on ethical consumerism, food commodification, certification and marketisation. In other words, alternative approaches largely reminiscent of what Elizabeth Shove (2010) calls the ABC policy model whereby 'social change is thought to depend upon values and attitudes (the A), which are believed to drive the kinds of behaviour (the B) that individuals choose (the C) to adopt' (Shove, 2010, p. 1274). This policy model relies on the intentionality of human behaviour for its assumed environmental and sustainability benefits. While $A B C$ model-based alternatives have spread throughout Eastern Europe since the 1990s, the key point about this region's agro-food alternatives is, as we show below, that the region harbours 'implicit', 'quiet' alternatives that do not result from intentional, individualised behaviours motivated by environmental and social responsibility.

Shove (2010) criticised the dominance of the $A B C$ model in these narratives of transformation. She argued that approaches based on the $A B C$ model are 'incapable of conceptualising transformation in the fabric of daily life on the scale and at the rate required' (Shove, 2010, p. 1283). Indeed, the solutions based on the $A B C$ model in the area of food and agriculture seem to have had a limited effect as only one per cent of the world's food market is accounted for by organic and fair trade food (Clapp, 2016). These approaches have also been subject to critique for the inequitable nature of these approaches as the higher costs associated with such alternatives have a socially exclusionary effect. Hence there is a need, as Shove (2010) also argued, to expand the scope of investigation from which alternative models of change can be developed. The remainder of this paper offers one such possible line of enquiry.

\section{Moving beyond the 'mainstream alternative' with concepts from research in the European East}

The theoretical choices that researchers make imply certain representations of the world (Gibson at al., 2010) and can have real effects in terms of which development pathways their research can illuminate and how these pathways are presented (Gibson-Graham, 2014). Furthermore, social sciences are performative-simultaneously reflecting and creating social reality (Law and Urry, 2004; Gibson et al., 2010). When it comes to the alternatives to conventional food systems developed in the Western context, abstract representations are not innocent academic constructs. The methods and concepts used in studies are political (Law and Urry, 2004) and might even be harmful to local solutions rooted in culture that cannot be subsumed into globally dominant interpretations and commodified perceptions of food. At the same time, as noted in the Introduction normative thinking is widespread in East European countries in terms of the perception of imported Western practices as an uncritically accepted model. As an academic practice, this enables scientific colonisation (Wessely-Csepeli, 1992) by unreflectively accepting the rationalities, theoretical models, methodologies, conceptualisations and distribution of resources from the West. Thus, harnessing concepts from diverse non-Western contexts can help scholars to raise the performance of alternatives and maintain localities. 
However, it is not easy to develop academic conceptualisations that would be equally valid to all contexts they are supposed to represent. Evidence of this is that, despite the benefits the greater diversity of concepts associated with alternative food practices would bring to theory, much of the existing social science scholarship revolves around a set of key concepts. This is partly so because it is tempting to squeeze the observed messiness under a set of familiar, well-defined discourses that allow scholars to organise and structure reality neatly (Gibson-Graham, 2014). This approach promises results that are relatable to what is already known. However, such focus on a set of key concepts derived from a limited social context also results from structural and discursive power relations. As Boaventura de Sousa Santos (2004) puts it when explaining sociology of absences, some notions are so dominant in the knowledge hierarchy that they are used to structure all other ideas or findings. Everything else that is not clearly relatable to these dominant notions is to some extent non-existent. Nowadays, ideas that are global and linked to capitalist logic are in this dominant position (Santos, 2004). These ideas set the 'guiding dynamics' of any discussion (Gibson et al., 2010). Consequently, 'knowledge from the periphery' is pushed to the background, and if it is to emerge from non-existence a more concerted effort is needed to push it forward. Recognition of the diversity of practices slipping through the dominant framings is important if researchers are to present the full spectrum of alternatives for structuring agro-food systems.

At this point we need to take an important detour to explain why we leave out of this discussion academic accounts of agro-food alternatives published in East European languages. As explained in the Introduction, this paper is concerned with the insights from research in Eastern Europe to shape general, international academic debates on agro-food alternatives. Echoing Sari Hanafi's (2011, p. 291) observation about the dilemma researchers from non-English speaking societies face summarised as 'publish locally and perish globally vs publish globally and perish locally' we would claim that there is almost no chance that a local debate on agro-food alternatives conducted in an East European language translates into a global theory-generating contribution. Since the researchers' location (Western or Eastern) is only of secondary importance for our argument as it is knowledge from the East in general that is marginalised, not necessarily knowledge produced by East European scholars, another important obstacle for this scholarship to be recognised as 'universaly' valid knowledge is tendency of high-profile international journals to 'publish orthodox and institutionally approved intellectual viewpoints, rather than "heretical" ones', subsequently '[l]ittle space is left for creativity or eccentricity', as Hanafi (2011, p. 303) pointed out writing from another peripheral region (the Arab East).

The hegemonic concepts currently dominating the discussions on alternative practices in agro-food systems have enabled scholars to develop fruitful debates on the possibility of the agro-food system's change. However, it also needs to be recognised that researchers who have been using these concepts (which does not exclude some previous work by the authors) are partly responsible for creating the phenomenon they are studying and that by doing so they are neglecting alternatives emerging from 'peripheral' (i.e. non-Western) contexts. In Eastern Europe, significant parts of food flows cannot be understood without seriously addressing exchanges rooted outside of formal (market) economic relations and other informal social relations as well as large sections of the population's almost spiritual relations to land, forest and food. In contrast to food systems in the European West, large sections of the population in the European East continue to have a personal attachment to agriculture and rurality and to engage with food provisioning on multiple levels - growing, processing, preserving, sharing and consuming food as part of their daily lives (see, for example, Grivins, 2016; Balázs, 2018; 
Jehlička et al., 2013). Rather than commodity-defined and single-point (i.e. purchase), their relationship with food has multiple entrance points. We argue that engaging with this diversity of foodways is what gives this paper on agro-food systems in the European East potentially wider (i.e. region transcending) resonance and significance. While a few separate publications have recently made tentative attempts to build theory from the East, this paper seeks to transcend these individual accounts to take stock of such attempts by bringing together several studies and tease out some overarching, more general insights of potential relevance to other regions. It also seeks to reflect more on these efforts in light of current debates on the politics of knowledge production (Keim, 2008, 2011, 2016; Santos, 2004).

\section{Evidence from Eastern Europe}

This paper's main contention is that food system scholarship would greatly benefit from insights from research on diverse agro-food practices in peripheral, non-Western contexts. Although Eastern Europe is one such context, East European agro-food practices that we consider inspiring have not attracted much attention among the international research community. At the root of this neglect might be the mismatch between these East European practices and the dominant alternative approach based on the $A B C$ model. In contrast to this, however, we believe the insights from the three cases presented below are valuable precisely because they sidestep the $A B C$ model. They offer new impulses and opportunities for contemplating possible transformations of the dominant food system based on already existing and common agro-food alternatives.

\subsection{The symbiosis of small and large-scale farms}

Drawing on insights from Russia and Ukraine, the first illustrative case demonstrates the possibility of the relationship between large farms and smallholders that defies what is often seen as conventional wisdom-a gradual consignment of small farms into the dustbin of history as a result of economic development and modernisation of agriculture (Boyce, 2006). Particular power relations within East European food systems offer a fundamentally different view on the relationship between large- and small-scale farms from the prevailing view in Western Europe or North America. Studies on the latter regions treat large- and small-scale farms and conventional and alternative agro-food networks as worlds apart (Whatmore, 1995; Raynolds, 2000; see Adnan [2013] and Bernstein [2004] for such an approach beyond the West), with their interaction framed in terms of confrontation and resistance. Referring to the US case, Patricia Allen and colleagues even use the metaphor of tectonic plates to refer to the (supposedly) sharp rift between conventional (mostly medium- to large-scale) and alternative (mostly small-scale) agro-food configurations in the West (Allen et al., 2003). The two systems are seen as each having their own production logic and very different input and output channels.

In contrast to this, the small-scale farms (e.g. subsidiary household plots) in the former Soviet Union held by rural dwellers coexisted with large state and collective farms where these household plot holders were officially employed. The small plots proved to be remarkably productive. Household plots accounted for only a minimal percentage of total agricultural land (less than one per cent in Russia), and their cultivation relied on their holders' manual labour. In contrast with the mechanised, 
large-scale farms, however, these plots were able to produce no less than a fifth to a quarter of agricultural production in most countries of the former Soviet Union (Spoor and Visser, 2001).

Many Western observers interpreted the large share of agricultural output coming from household plots in the socialist past as a sign of the efficiency of private, family farming compared to the inefficiency of collective or state farming. Although there was a degree of validity in this explanation, this interpretation, which fitted in with the dominant conceptualisation in the West of family farms as efficient agricultural units, led many observers to overlook the complex interactions between the large farms and household plots. As Grigor Shmelev $(1971,1986)$ and Western Sovietologists drawing on his research such as Karl-Eugen Wädekin (1967) and Stefan Hedlund (1989) showed, these household plots flourished due to the symbiosis that existed between them and the large-scale farms. ${ }^{8}$

Although the socialist era put an end to the peasantry in its classic understanding, smallholders survived and constituted one of the pillars of symbiosis described above. 'Smallholders' primarily refers to some 15 million Russian rural household plot producers. ${ }^{9}$ After the dissolution of collective farms during the liberal reforms of the 1990s, the issue of the fate of those smallholders and their ties with large farm enterprises (LFEs) arose. The advice by Eastern European reformers and their Western advisors in the 1990s was that privatised collective farms should either disband and split up (mostly in Central and Eastern Europe) or downsize (mostly in the former Soviet Union) and preferably eradicate all their social functions, described as 'backward', 'inefficient' and non-core business (Kwiencinski, 1998; for a critical analysis, see also Visser [2006]).

In the course of decollectivisation in the 1990s, often referred to as 'agricultural restructuring', a third actor-private individual/family farmer-was added to the Soviet bimodal agrarian structure. Creating a large stratum of family farmers was an important aim of the liberal agrarian reforms in the 1990s. In reality, the results have been rather modest, as in the 2010s family farmers produced some ten per cent of Russia's agricultural GDP. Most rural dwellers did not embark on commercial family farming but chose to preserve their household production, often combining it with a wage job in an LFE, as that meant that they could continue to benefit from the symbiosis with the LFEs (Visser, 2010).

The collective and state farms were converted into private enterprises of various organisational forms (such as joint-stock companies; all of which are, in this paper, referred to as LFEs). Despite a slump in production in the 1990s, those successors of the Soviet collective farms remained the main agricultural producers in Russia. At the same time, the role of household plots rose dramatically during the market reforms of the 1990s, as they became the major source of subsistence for the impoverished rural population (Caskie, 2000; Visser, 2010; Visser et al., 2015). Overall, household plots have maintained a significant role in supplying Russian households with food. In 2016, for example, Russian household gardeners produced about 35 per cent of the total food production in the country-an output that was primarily self-consumed (Wegren, 2018). Thus, the Soviet bimodal agrarian structure mainly persisted in the post-Soviet era.

Since the early 1990s, however, the Soviet-era symbiosis has undergone gradual transformations (Nikulin, 2003; Pallot and Nefedova, 2007; Kurakin, 2015). Many weaker LFEs preserved a Soviet-style paternalistic logic of supporting households (Nikulin, 2003; Visser, 2003, 2006). Their inability to achieve efficient economic performance, and therefore to provide their workers with sufficient income, led to an informal agreement: resources for loyalty. Stronger LFEs, on the other hand, tried to reduce that paternalistic symbiosis (including petty thefts, which were widespread in collective 
farms) and to shift towards purely market-based and contractual relations. Furthermore, the postSoviet reforms transferred responsibility for social services from LFEs to municipalities, but without providing the latter with additional finance. Consequently, they fell in decline unless the local LFEs had the resources and willingness to maintain (part of) it (Nikulin, 2011).

In sum, the smallholdings in the state socialist agrarian systems in the former Soviet Union and some parts of Central and Eastern Europe mostly had a symbiotic relationship with the LFEs (Nikulin, 2003). Such symbiosis often lingers in a reduced form in those countries and regions were large-scale farms have persisted (e.g. large parts of the former Soviet Union, such as in Russia, Ukraine and Kazakhstan) or rapidly re-emerged (e.g. Romania). A close-up view of agriculture in the European East, therefore, suggests that although frictions exist large- and small-scale farms often co-exist and frequently interact in manifold ways. This insight from the East European context challenges both the mainstream orthodoxy supporting the relentless drive towards large-scale, corporatised farming and food processing sector and the alternative relocalised and small-scale food provisioning on the margins of corporatised farming and also shows the possibility of co-existence of the two. Such co-existence can potentially offer a variety of economic, social and environmental benefits. For instance, large farms can offer employment (with added benefits such as pensions) from which smallholders who are also farm workers can benefit (Pallot and Nefedova, 2007). Beyond that, large farms may also offer rural social infrastructure as well as marketing and machinery services to smallholders (Pallot and Nefedova, 2007; Nikulin, 2011; Visser et al., 2019). The provision of fodder and/or machinery services by large farms to smallholders enables the latter to increase production while still maintaining a mostly ecological production (Visser et al., 2015). Such insights from the European East inspire questions about the potential benefits of such symbiosis in other social contexts outside the countries of the former Soviet Union.

\subsection{Informal food cultures: self-provisioning and sharing}

Using insights from research conducted in the Central and East European part of the European East (i.e. in Czechia, Poland and Hungary), this section highlights the importance of informal economic food practices for the food system and its possible future development trajectories. Some 20 or 25 years after 1989, 38 per cent of the Czech population (in 2015; Jehlička and Daněk, 2017), 36 per cent of Hungarians (in 2013; Visser, 2016) and 54 per cent of Poles (in 2011; Smith and Jehlička, 2013) grew food in their households. Project-based food production and distribution initiatives such as community-supported agriculture and community gardening schemes in Western contexts are associated with younger, educated, upwardly mobile and middle-class people. In contrast, 'evolved', 'intrinsic' informal food provisioning and inter-household sharing have typically been viewed by Western-based researchers as survival and coping strategies of disadvantaged strata of East European societies (e.g. Alber and Kohler, 2008) and as residual practices of rural and less well-off segments of the population in the Global North (Teitelbaum and Beckley, 2006). In the 1990s and 2000s, these alternatives were deemed to be uninspiring and lacking relevance for the food system's innovation and theorisation. In an extreme case, they were considered as evidence of East European societies' demodernisation (Rose and Tikhomirov, 1993).

Furthermore, the possible environmental benefits of these practices have also been dismissed. A Czech government strategy document on rural development stated: "Ineffective self-provisioning 
habits (eggs, poultry, potatoes, vegetables, fruit) hang over from the past, which contributes to the relatively low purchasing power of the countryside" (Ministerstvo pro místní rozvoj a Ministerstvo zemědělství, 2000, p. 18) and "food self-provisioning, which provides households involved in this activity with a basic livelihood, can sometimes contribute to decline and exclusion" (ibid, 43). Contrary to these expectations, however, these food practices failed to disappear with the completion of the macro-scale economic and political transformation of East European societies in the late 2000s (Jehlicka et al., 2013). In terms of ecological benefits, such practices rely on closed-loop nutrient cycling, promote agrobiodiversity, and illustrate the radical potentials of non-market-based seed- and food-provisioning (Balázs, 2018; Balázs and Aistara, 2018).

Since the mid-2000s, there has been a growing sense of unease, both in Western societies and sections of academia, about the effects of expanding middle classes and consumption in 'emerging economies' in Asia and Africa. These anxieties are borne out of concerns about geopolitical shifts in political and economic power but also about the effects of these trends for the environment and sustainability. It is assumed that economic growth, the development of market economies, and the associated rise of middle classes and consumption lead to the demise of informal sustainability-compliant practices such as household food production and distribution (Acheson, 2007; Alber and Kohler, 2008). Importantly, the lessons from Eastern Europe show that this may not necessarily be the case. Confirming the marginal standing of CEE as a theory generative-context, it is often overlooked in these discussions that East European societies underwent similar processes of middle-class expansion and increases in consumption in the 1990s and 2000s. And yet, the number of people practising food self-provisioning (FSP) and engaging in informal food distribution networks has not necessarily declined. According to research conducted by Joe Smith and his colleagues in Poland and Czechia in the first half of the 2010s:

"[t]he middle-class food self-provisioners of post-socialist CEE have been defying expectations of their new-formed class. Roughly forty per cent of them are growing roughly forty percent of some types of their own food (e.g. potatoes; soft fruit; eggs). These consumption practices are happening 'in the wrong time and the wrong place' [...] From the point of view of the architects of post-socialist transition the fact that the middle classes continue to grow their own food almost has the status of deviance" (Smith et al., 2015, p. 231).

While the environmental benefits, including an extreme form of food relocalisation and uncertified organic food production (Smith and Jehlička, 2013) of East European informal food practices, are rarely considered explicitly, they are significant. For example, the replacement of purchased with homegrown vegetables results in the saving of as much as $2.1 \mathrm{~kg} \mathrm{CO}{ }_{2}$ eq per $\mathrm{kg}$ of vegetables (Vavra et al., 2018). These environmental benefits are an example of how knowledge produced in East European societies can make an important contribution to our understanding of sustainable food systems in terms of David Schlosberg and Romand Cole's (2016) notions of 'sustainable materialism' and everyday practices around food and energy flows.

These East European food practices also have the capacity to strengthen social cohesion. For example, recent research into informal food distribution based on a large-scale national survey conducted in Czechia revealed that 64 per cent of food-producing households share a portion of what they produce with others (Jehlička and Daněk, 2017). Respondents to the survey acknowledged and valued the social ties established and maintained through food sharing, with social motivations cited more often than feelings of obligation as the primary reason for sharing food: 31 per cent of households that shared more than $1 / 10$ of their production cited "the joy of pleasing other people" as their reason for 
doing so, while 13 per cent claimed they did so "to maintain good relations with friends and neighbours", nine per cent said it was "to enjoy time with friends", and seven per cent wanted "to present the results of my labour". Sharing behaviour was found to be similar across all social groups and was not significantly conditioned by class, income, or education level. In addition, there was no evidence of food transfers from the rich to the poor.

Food-sharing networks are, for the most part, non-reciprocal in nature 51 percent of households participate in these networks only as recipients. Although family relations play an important role in these sharing networks, they are not limited to extended family members: two-thirds of food-sharing households were part of networks in which at least one member was not a relative. More than one fifth of households participated in networks that did not include any other family member.

FSP represents a radical shortening of the food chain from farm to fork and an extension of access to food beyond the household to the wider family, the community and the ecological conditions in which self-producers and prosumers are embedded. The shared customary social organisation of these practices is based on the values of caring, collectiveness, stewardship of the land, and family. Thus, through these practices, Eastern European societies seem to be nurturing values necessary for individual, collective and social sustainability (Balázs, 2016; Balázs et al., 2016). Research into East European informal food production and distribution shows how these societies can make a significant contribution to our knowledge on food security, public health and social cohesion. These practices have positive outcomes in the form of reduced resource consumption and pollution. They invite us to think of sustainability in ways different to those associated with virtues of limitations and constraints on resource use and consumption and instead highlight abundance, enjoyment and exuberance. Findings from researching East European informal practices can have a significant impact in terms of rethinking informality, food relocalisation, social resilience and sustainability concerning socioeconomic processes such as the growth of middle classes and consumption. FSP also implements democratic changes into the food system without advocating the need for its radical transformation (De Hoop and Jehlička, 2017). Production for one's own consumption and for sharing with others is an expression of the democratic food system and a method to regain control over what people eat, as it extends to all ages and income groups and transcends the rural-urban divide.

\subsection{Foraging cultures: the role of wild products}

In mainstream agro-food studies, food tends to be perceived through the lens of cultivation and agriculture. Combined with the fact that foraging is considered a marginal practice in the context of the Western 'core' in which conceptual and theoretical agro-food knowledge is produced, this situation has resulted in limited attention to wild food products. Sourcing food from the wild has been regarded as being of secondary importance, representing lifestyle activities that should not be attributed to the functioning of food systems. Interest in wild harvests has been limited to a few cash products (such as boletes, wild bilberry, and cork) (Maes et al., 2012; Bonet et al., 2014; Schulp et al., 2014). Consequently, research discussing wild products remains limited. The limited material that there is mainly engages with wild product foraging as an activity pursued by small groups of people with specific lifestyle choices (Peintner et al., 2013; Bardone and Pungas-Kohv, 2015).

By far the most pronounced interest in wild products comes from attempts to identify new forest management practices or as a part of growing interest in environment and ecosystems (Maes et al., 
2012; Schulp et al., 2014). In both of cases, wild products are identified as a resource that needs to be taken into account in the discussion of humans' relationships with nature. In other words, the practice of foraging is not what these approaches are focused on, which partly explains the lack of current agro-food scholarship's engagement with the social significance of foraging and with the role these products play in local and global food systems.

As a result of the limited research engagement with the topic, there is insufficient comparative data on the prevalence of foraging. Nevertheless, some indicators point to East and North European populations being significantly more involved in wild product foraging than populations in other parts of Europe (Vidale et al., 2016). This high involvement goes hand in hand with an in-depth tacit knowledge people in these countries seem to have about forest flora (Łuczaj and Szymański, 2007; Peintner et al., 2013). In North and East European societies more plants and fungi are recognised as valuable and edible and more information is available in public domains about how these products can be utilised. ${ }^{10}$ Recognised wild products differ minimally across the region. For example, the evidence from Latvia, Estonia and Belarus illustrates that products foraged in these countries are often the same. For example, a number of berry species are picked-bilberries, raspberries, lingonberries, cranberries, blackberries and blackthorns. Among mushrooms, boletes and chanterelles are the most popular species. However, there are countless other mushroom species with which citizens are familiar and which they pick. And finally, tree products (such as nuts, bark, and lime blossoms) and culinary and pharmaceutical plants are also foraged. Some of these products, like bilberries, boletes and chanterelles, have in recent years become commodities traded in global markets and a source of income for segments of the rural population in the region.

The diversity of the foraged products suggests that there are several ways people become involved in wild product foraging. This diversity also means an extended foraging season and multiple ways in which these products can be used. The foraging culture has partly survived in the region due to political developments of the 20th century, including the regular economic shocks rural communities were exposed to, the failure of the Soviet food system to provide a reliable supply of food for the population, and the institutional support for foraging during the Soviet era. The fact that a large proportion of the territory of many of these countries is covered with forests is an important factor as well (Grivins, 2016).

While there are differences among East European countries regarding the degree of people's involvement in foraging, it is foraging's social significance in this region that distinguishes these countries from the rest of Europe. In Latvia and Estonia, the practices associated with wild products are strongly tied to local identities and cultures. ${ }^{11}$ People living in Eastern Europe have maintained the knowledge of how to identify, pick, process, preserve and consume wild products across generations (Łuczaj and Szymański, 2007; Łuczaj and Nieroda, 2011; Kovalcik, 2014; Bardone and Pungas-Kohv, 2015; Grivins and Tisenkopfs, 2018). For most inhabitants, picking wild products is motivated by a desire to 'embrace wilderness'. While wild products also serve to diversify diets for people living close to forests (Bardone and Pungas-Kohv, 2015), in most cases these products do not account for high proportions of recommended nutritional intake (although in Latvia the estimated harvest of wild berries is close to the harvest of commercially produced apples [Grivins, 2016]).

Even in the cases where these products are becoming a part of more complex socio-economic systems with global reach (in other words, where they become a part of global food chains), foraging remains a localised activity. ${ }^{12}$ Research has shown that in the European East even when wild products are 
integrated into global supply chains the forager continues be embedded in a particular localised community-a group of people benefitting from local flora and habitats and demonstrating particular skills needed to find and ascertain mushroom, berry and herb species (Grivins, 2016). Knowing the best mushroom and berry spots, having a trained eye to spot wild products in their natural habitat, and being educated in different applications of various products are skills that can be obtained by practising them under the guidance of an experienced forager.

Engagement with wild products is very personal. Most of the knowledge needed for foraging is context-specific and passed down from generation to generation, and thus, as a localised practice, it strengthens intergenerational connections. It also creates new ties to the surrounding environment and nature and offers new ways in which people relate to the food they consume. While some technological and organisational platforms supporting people engaging with wild products (such as apps or online communities to support the identification of mushrooms, educational foraging tours and equipment for foragers) do exist, such platforms are less common. In countries like Latvia, Estonia and Belarus, the absence or light presence of official organisational structures result from the traditionally very open regulations (open access to forests; no limitations on what, how or how much to pick; poorly regulated and monitored trade in wild products) and thus the lack of need for such structures. Overall, foraging remains an activity that does not depend on technology and organisation to perform its functions.

\section{Discussion}

In their study 'Post-socialist economic geographies and the politics of knowledge production', John Pickles and Adrian Smith extolled Eastern Europe as a place with 'the incredible melange of practices, rhythms and identities' the dynamics of which suggest 'that something new is underway, something old is being sustained, and something that combines the two is emerging' (Pickles and Smith, 2007, p. 152). Taking a look at the specific subfield of agro-food studies, this paper shows that more than a decade later Eastern Europe has lost little of its potential as an inspiring and novel knowledgeproducing social context.

Food provisioning in Eastern Europe offers opportunities for studying community-level interactions and the diverse ways in which people relate to food. Perhaps even more striking is the affinity with concerns that have recently begun to define large sections of Western alternative food scholarship. These include household-level sustainability, everyday life, food provisioning as social practice (Evans, 2018), and the 'post post-material environmentalism' and 'sustainable materialism' manifested in research on everyday material and energy flows (Schlosberg and Coles, 2016).

This melange of everyday practices, both traditional and new, also enables us to think of East European informal food practices in terms of their significance for food security and social resilience. In the academic literature, food insecurity and household-level coping strategies are deemed to relate to the vulnerability of livelihoods and poverty. Drawing on Amartya Sen's $(1981 ; 1984)$ notion of the 'endowment set', it can be argued that due to their more diverse endowment sets East European food systems are remarkably resilient as compared to the societies in the 'centre' or West. The combination of options for obtaining food via exchange (people use their labour to purchase food), transfer (people use their membership in a local community to obtain food as a gift), and production (using land and 
skills people produce or forage their own food) gives these societies a unique opportunity for experimentation and creativity-processes that should inspire scholars both within and beyond the region. At least in some countries of the European East, the food system's resilience is further enhanced by the symbiotic relationship between LFEs and smallholders. ${ }^{13}$

The presented food practices are not marginal in East European societies. Quite the opposite; they are socially prevalent and a considerable source of food. Hence the question arises, why have they been, until very recently, practically absent from academic debates and journals and pan-European research calls? Compared to the hegemonic West-European (or North American) context for agrofood studies, Eastern Europe can be thought of as representing significant (although not unbridgeable) 'difference'. One key specificity of the East European food system is its multiplicity, which goes beyond the economic dimension (see, for example, Balázs, 2018 and Balázs and Pataki, 2018). Moreover, there have been attempts at various tactics to deal with this difference in epistemological perspectives (e.g. Wessely and Csepeli, 1996). One potential avenue for reporting on this East European experience, both to the West and East, ${ }^{14}$ could be combinations of controversial genres such as sociography, poetical-intellectual endeavours, policy-based research and social reform programmes. However, most often this 'cognitive chance' for knowledge generation has been largely missed.

Furthermore, in the context of accelerated academic competitiveness, it is what can pass relatively easily through the peer review process and hence what matches mainstream expectations that count as valued and accepted knowledge. Topics, arguments and concepts perceived as marginal and/or not perceived as immediately transferable tend to be avoided as they pose risks to the researchers exploring them. As a result, agro-food scholarship seeking to develop original insights from the European East that would resonate beyond the region encounters two difficulties. First, it has to challenge the expectation that conceptualisations, theories and evidence from the European West are directly relevant for research in Eastern Europe. Second, the global academic community expects findings made in investigating the European East to be useful mainly as confirmations and extensions of knowledge developed in the West. The discussion of the three cases in this paper sought to demonstrate the possibility of adopting an equal approach in knowledge production.

\section{Conclusions}

Many food practices which in the Western context are limited to a 'niche' and have interstitial, precarious, marginal, and residual qualities (Tornaghi, 2017) are an everyday and socially widespread occurrence in East European societies. Hence it would appear that, in many ways, Eastern Europe could and probably should be a context in which much of this alternative food scholarship-in the form of theories, concepts and epistemologies-originates. However, for a number of reasons, some of which have been touched upon but whose comprehensive elaboration transcends the scope of this paper, the question 'what can we learn from "the East"?' (Spoor, 2012) has largely been avoided. Instead, food and agriculture studies in the East European context, regardless of whether conducted by scholars based in Eastern or Western Europe, has until recently tended to use the European East as a contributory testing ground for concepts and research agendas developed in the West.

This paper is a contribution to growing efforts (e.g. Mincyte, 2011, 2012; Aistara, 2015; Pungas, 2019; Visser et al., 2019) to go beyond an approach that renders East Europe as primarily an object rather than a subject of research and to examine how knowledge production in Eastern Europe is 
marginalised. By outlining several examples selected from our own engagement with food and agriculture studies in Eastern Europe we seek to highlight the significant potential of findings and knowledge produced in Eastern Europe for food scholarship and theory building on food issues more generally.

We see Eastern Europe as a place in which novel food practices and institutional arrangements emerge that are based on the enmeshing, entangling and mutual reinforcing of binaries usually considered to stand in opposition to each other. These include the formal and informal, traditional and modern, market and non-market, and local and global processes. This makes the region a source of critical thinking about alternative food systems and food provisioning strategies that combine these elements. The prevalence of food self-provisioning and the symbiosis of large farm enterprises and household smallholdings are cases in point as is the strong but changing foraging culture in which traditional identity and culture are increasingly exposed to global economic interests and technological innovations.

The examples explored in the paper suggest that research on agro-food systems and food-related practices in East European countries can make a significant contribution to knowledge and inform wider debates on environmental sustainability and social cohesion. These practices are located either outside the market or at the intersection of the formal market and non-market economies, often beyond both the state and institutions of civil society. They invite us to consider much more seriously the implications of everyday practices for sustainability and resilience and the importance of practices that straddle the divide between work and leisure-practices that foster social bonds, that confer on people pride of their knowledge, skills and achievements, and that allow them to enjoy social interactions.

More specifically, extrapolating from the three case studies at the centre of this paper, we suggest that research on East European agro-food alternatives could contribute to the development of international theorisations concerning:

- the effects of complementarity and interdependency among several ways of obtaining food exchange, transfer and production (as opposed to the dependence on just exchange) for practitioners' creativity and experimentation and the food system's change engaging resilience (for preliminary work on this see Visser et al. [2019a]);

- the understanding of formal market and informal activities as often interdependent rather than separate;

- the potential for theorisations from non-activist, everyday, unintended forms of sustainability (sustainability by outcome rather than intention) and the importance of routinised behaviour for the maintenance and diffusion of these practices (useful insights on this can be found in Veen et al. [2014]);

- the potential for learning from the fact that these alternatives have thrived in East European there were very diveres in terms of their social contexts both before and after 1989 and that thrived during the extremely turbulent post-1989 decades. Learning from this experience is of huge significance in temporal sense in terms of unpredictable but certainly turbulent future and also spatially as these practices are prevalent in many rising powers such as China.

We would also argue that these efforts would be strengthened, on the one hand, by the willingness of scholars investigating East European agro-food topics to adopt an inductive approach to their research rather than starting from concepts and theories developed in other social context (in 
reality, primarily in the Western "centre") and, on the other hand, by international journals' greater receptivity and sensitivity to less orthodox research viewpoints.

Acknowledgements Petr Jehlička's work on this paper was supported by the Czech Science Foundation, Czechia [grant \# GA19-10694S]. He also worked on part of this paper while holding Visiting Scholarship at Helsinki University's Ruralia Institute in Mikkeli, Finland in April 2019. Mikelis Griviñš's work was supported by the ERAF Post-doctoral Research Support Program [project Nr. 1.1.1.2/16/I/001, research application Nr. 1.1.1.2./VIAA/1/16/155]. The authors would like to thank Colin Kimbrell for making this article a smoother read.

\section{REFERENCES}

Acheson, J. (2007) Household Exchange Networks in Post-Socialist Slovakia. Human Organization, 66 (4): 405-413.

Adnan, S. (2013) Land grabs and primitive accumulation in deltaic Bangladesh: interactions between neoliberal globalization, state interventions, power relations and peasant resistance, Journal of Peasant Studies, 40 (1): 87-128.

Aistara, G. (2015) Good, clean, fair ... and illegal: paradoxes of food ethics in post-socialist Latvia, Journal of Baltic Studies, 46. 283-298.

Alber, J. and Kohler, U. (2008) Informal food production in the enlarged European Union. Social Indicators Research 89 (1), 113-127.

Allen, P., FitzSimmons, M., Goodman, M. and Warner, K. (2003) Shifting plates in the agrifood landscape: The tectonics of alternative agrifood initiatives in California, Journal of Rural Studies, 19 (1): 61-75.

Balázs, B. (2016) Food self-provisioning - the role of non-market exchanges in sustainable food supply. In: Meybeck, A. and Redfern, S. (eds) Sustainable Value Chains for Sustainable Food System. Rome: Food and Agricul-ture Organisation of the United Nations, pp. 73-78.

Balázs, B., 2016. Food self-provisioning: the role of nonmarket exchanges in sustainable food supply. In: Meybeck, A., Redfern, S. (Eds.), Sustainable value chains for sustainable food systems: a workshop of the FAO/UNEP Programme on Sustainable Food Systems. FAO, Rome, pp. 73-78.

Balázs, B., 2018. Community-building through food self-provisioning in Central and Eastern Europe: an analysis through the food commons framework. In: Vivero-Pol, J.L., Ferrando, T., de Schutter, O., Mattei, U. (Eds.), Routledge Handbook of Food as a Commons. Routledge, pp. 296-310.

Balázs, B., Aistara, G., 2018. The emergence, dynamics and agency of social innovation in seed exchange networks. The International Journal of Sociology of Agriculture and Food 24 (3), 336-353.

Balázs, B., Pataki, Gy., 2018. Cooperative research for the bottom-up food sovereignty and policy change. In: Bartels, K., Wittmayer, J. (Eds.), Action Research in Policy Analysis. Routledge, London, pp. 59-83. 
Balázs, B., Pataki, Gy., Lazányi, O., 2016. Prospects for the future: community supported agriculture in Hungary. Futures 83, 100-111.

Bardone, E. and Pungas-Kohv, P. (2015) Changing Values of Wild Berries in Estonian Households: Recollections from an Ethnographic Archive. Journal of Baltic Studies, 46, 319-336.

Bernstein, H. (2004) Changing before our very eyes: Agrarian questions and the politics of land in capitalism today. Journal of Agrarian Change, 4 (1-2): 190-225.

Blandford, D. and K. Hassapoyannes (2018) "The role of agriculture in global GHG mitigation", OECD Food, Agriculture and Fisheries Papers, No. 112, OECD Publishing, Paris. http://dx.doi.org/10.1787/da017ae2-en

Blazek, M., Šuška, P. (2017) Towards dialogic post-socialism: Relational geographies of Europe and notion of community in urban activism in Bratislava. Political Geography, 61, 46-56.

Bonet, J. A., Gonzalez-Olabarria, J. A. and De Aragón, J. M. (2014) Mushroom production as an alternative for rural development in a forested mountainous area. Journal of Mountain Science, 11(2): 535-543.

Boyce, J. K. (2006) A future for small farms? Biodiversity and sustainable agriculture, in Boyce, J. K., Cullenberg, S., Pattanaik, P. K. and Pollin, R. (eds) Human Development in the Era of Globalization, Edward Elgar: Cheltenham, 83-104.

Bruinsma, J. (ed). (2003). World Agriculture: Towards 2015/2030. An FAO perspective. Earthscan Publications Ltd

Caskie, P. (2000). Back to basics: household food production in Russia. Journal of Agricultural Economics, 5, 196-209.

Clapp, J. (2016) Food. Cambridge: Polity Press.

Comaroff, J. and Comarrof, J. (2012) Theory From The South: Or, How Euro-America Is Evolving Towards Africa. Abingdon: Routledge.

Connell, R. (2007) Southern theory: the global dynamics of knowledge in social science. Cambridge: Polity Press.

De Hoop, E., Jehlička, P. (2017) Reluctant Pioneers in the European Periphery? Environmental Activism, Food Consumption and "growing your own". Local Environment 22 97): 809-824.

Evans, D. (2018) Rethinking material cultures of sustainability: Commodity consumption, cultural biographies and following the thing. Transactions of the Institute of British Geographers, 43, 110-121.

Garnett, T. (2011) Where are the best opportunities for reducing greenhouse gas emissions in the food system (including the food chain)? Food Policy 36, 23-32.

Gibson, G., Cahill, A. and D. McKay. (2010). Rethinking the dynamics of rural transformation: performing different development pathways in a Philippine municipality. Transactions of the Institute of British Geographers, 35(2): 237-255.

Gibson-Graham, J. K. (2014). Rethinking the Economy with Thick Description and Weak Theory. Current Anthropology, 55(9): 147-153. 
Grivins, M., 2016. A comparative study of the legal and grey wild product supply chains. Journal of Rural Studies 45, 66-75.

Grivins, M., Keech, D., Kunda, I., Tisenkopfs, T., 2017. Bricolage for Self-Sufficiency: An Analysis of Alternative Food Networks. Sociologia Ruralis 57 (3), 340-356.

Grivins, M., Tisenkopfs, T., 2018. Benefitting from the global, protecting the local: The nested markets of wild product trade. Journal of Rural Studies 61, 335-342.

Gruère, G., C. Ashley and J. Cadilhon (2018-09-05). "Reforming water policies in agriculture: Lessons from past reforms", OECD Food, Agriculture and Fisheries Papers, No. 113, OECD Publishing, Paris. http://dx.doi.org/10.1787/1826beee-en

Hanafi, S. (2011) University systems in the Arab East: Publish globally and perish locally vs. publish locally and perish globally. Current Sociology, 59 (3): 291-309.

Hann, C. (2003) Introduction: Decollectivisation and the moral economy. In C. Hann and the 'Property relations' group The Postsocialist agrarian question. Property relations and the rural condition. Halle studies in the anthropology of Eurasia, pp. 1-47. Munster: LIT Verlag.

Hedlund, S. (1989) Private agriculture in the Soviet Union. London, New York: Routledge.

Humphrey, Caroline (1983). Karl Marx Collective.; economy, Society and Religion in a Siberian Collective Farm. Cambridge: Cambridge University Press.

Jehlička, P., Kostelecky', T., Smith, J. (2013) Food Self-Provisiong in Czechia: Beyond Coping Strategy of the Poor: A Response to Alber and Kohler's 'Informal Food Production in the Enlarged European Union' (2008) Social Indicators Research, 111, 219-234.

Jehlička, P.; Daněk, P. (2017) Rendering the Actually Exisiting Sharing Economy Visible: Home-Grown Food and the Pleasure of Sharing, Sociologia Ruralis, 57(3), 274-296.

Keim, W. (2008) Distorted universality - internationalization and its implications for the epistemological foundations of the discipline. Canadian Journal of Sociology/Cahiers canadiens de sociologie, 33: 555-574.

Keim, W. (2011) Counterhegemonic currents and internationalisation of sociology: Theoretical reflections and an empirical example. International Sociology, 26: 123-145.

Keim, W. (2016) The international circulation of social science knowledge: Relevant factors for acceptance and rejection of travelling texts. Revue d'anthropologie des connaissances 10: a-aj.

Kovalcik, M. (2014) Value of forest berries and mushrooms picking in Slovakia's forests. Beskydy, 7, 39-46.

Kurakin, A. (2015) When the State is Shirking: Informal Solutions for Social Services Provision in Altai Villages. Przeglad Wschodnioeuropejski. 6(2), 145-159.

Kuus, M. (2004) Europe's eastern expansion and the reinscription of otherness in east-central Europe. Progress in Human Geography, 28 (4), 472-489.

Kwiencinski, A. (1998) The Slow Transformation of Russian Agriculture, The OECD Observer, no. 214, October/November, 35-38. 
Larner, W. (2011) Economic geographies as situated knowledges. In: Pollard, J., McEwan,C., Hughes, A. (Eds.), Postcolonial Economies: Rethinking Material Lives. Zed Books, London and New York, pp. 81106.

Law, J. and Urry, J. (2004) Enacting the social. Economy and Society, (33), 390-410.

Leake, J. R., Adam-Bradford, A. and Rigby, J. E. (2009) Health benefits of 'grow your own' food in urban areas: implications for contaminated land risk assessment and risk management? Environmental Health. 8, S6. https://doi.org/10.1186/1476-069X-8-S1-S6

Łuczaj, L. and Nieroda, Z. (2011) Collecting and learning to identify edible fungi in southeastern Poland: age and gender differences. Ecology of Food and Nutrition, 50(4), 319-336.

Łuczaj, L. and Szymański, W. M. (2007) Wild vascular plants gathered for consumption in the Polish countryside: a review. Journal of Ethnobiology and Ethnomedicine, 3:17.

Maes, J., Paracchini, M.L., Zulian, G., Dunbar, M.B. and Alkemade, R. (2012) Synergies and trade-offs between ecosystem service supply, biodiversity, and habitat conservation status in Europe. Biological Conservation 155, 1-12.

Mincyte, D. (2011) Subsistence and Sustainability in Post-industrial Europe: The Politics of Smallscale Farming in Europeanising Lithuania, Sociologia Ruralis, 51, 101-118.

Mincyte, D. (2012) How milk does the world good: vernacular sustainability and alternative food systems in post-socialist Europe, Agriculture and Human Values, 29 41-52.

Müller, M. (2018) In Search of the Global East: Thinking between North and South, Geopolitics DOI: 10.1080/14650045.2018.1477757

Müller, M. (2019) Goodbye, Postsocialism!, Europe-Asia Studies, DOI: 10.1080/09668136.2019.1578337

Nikulin, A. (2003) The Kuban Kolkhoz between a Holding and a Hacienda: Contradictions of Post-Soviet Development. Focaal, 41, 137-152.

Nikulin, A. (2011) From Post-Kolkhoz to Oligarkhoz. Vestnik RUDN, Sociological Series, 2, 56-68.

Pallot, J. and Nefedova, T. (2007) Russia's Unknown Agriculture: Household Production in Post-Socialist Rural Russia. Oxford: Oxford University Press.

Peintner, U., Schwarz, S., Mešić A., Moreau, P-A., Moreno, G. and Saviuc. P. (2013). Mycophilic or Mycophobic? Legislation and Guidelines on Wild Mushroom Commerce Reveal Different Consumption Behaviour in European Countries. PLOS ONE.

Pickles, J. and Smith, A. (2007) Post-socialist economic geographies and the politics of knowledge production. In Politics and Practices of Economic Geography. Edited by A. Tickell, E. Sheppard, J. Peck and T. Barnes. London: SAGE, pp. 151-162.

Pouta, E., Sievanen, T. and Neuvonen, M. (2006) Recreational Wild Berry Picking in Finland-Reflection of a Rural Lifestyle. Society and Natural Resources, 19, 285-304.

Pungas, L. (2019) Food self-provisioning as an answer to the metabolic rift: The case of 'Dacha Resilience' in Estonia, Journal of Rural Studies, 58, 75-86. 
Raynolds, L. (2000) Re-embedding global agriculture: the international lorganic and fair trade movements. Agriculture and Human Values 17, 297-309.

Rose, R., Tikhomirov, Y. (1993) Who grows food in Russia and eastern Europe? Post Soviet Geography, 34 (2), 111-126.

Roy A (2011) Slumdog cities: Rethinking Subaltern Urbanism. International Journal of Urban and regional Research, 35: 223-238.

Roy A (2016) Who's Afraid of Postcolonial Theory? International Journal of Urban and Regional Research, 40: 200-209.Santos, B. de Sousa (2004) The World Social Forum: toward a counterhegemonic globalisation (part 1) in Sen J, Anand A, Escobar A and Waterman P eds The World Social Forum: challenging empires Viveka Foundation, New Delhi 235-45

Schlosberg, D., and Coles, R. (2016) The new environmentalism of everyday life: Sustainability, material flows and movements. Contemporary Political Theory, 15, 160-181.

Schulp, C. J. E., Thuiller, W. and Verburg, P. H. (2014) Wild food in Europe: A synthesis of knowledge and data of terrestrial wild food as an ecosystem service. Ecological Economics, 105, 292-305.

Sen, A. (1981) Poverty and Famines: An Essay on Entitlement and Deprivation. Oxford:

Clarendon Press.

Sen, A. (1984) Resources, Values and Development. Oxford: Basil Blackwell.

Shmelev, G. (1971) Lichnoe podsobnoe khozaistov i ego svyazi s obshchestvennom proizvodstvom. Moscow: Mysl.

Shmelev, G. (1986) Personal subsidiary farming under socialism. Moscow: Progress Publishers.

Shove, E. (2010) Beyond the ABC: Climate Change Policy and Theories of Social Change. Environment and Planning A, 42 (6), 1273-85. DOI 10.1068/a42282.

Smith, J. and Jehlička, P. (2013) Quiet sustainability. Fertile lessons from Europe's productive gardeners. Journal of Rural Studies 32: 148-157.

Smith, J., Kostelecky' , T. and Jehlička, P. (2015) Quietly does it: questioning assumptions about class, consumption and sustainability. Geoforum 67: 223-232.

Smith, A. and Rochovská, A. (2007) Domesticating neo-liberalism: Everyday lives and the geographies of post-socialist transformations. Geoforum, 38: 1163-1178.

Sonnino, R. and Griggs-Trevarthen, C. (2013). A resilient social economy? Insights from the community food sector in the UK. Entrepreneurship and Regional Development, 25, 272-292.

Spoor, M. (2012) Agrarian reform and transition: what can we learn from 'the east'? The Journal of Peasant Studies, 39 (1): 175-194.

Spoor, M. and Visser O. (2001) The State of Agrarian Reform in the Former Soviet Union. Europe-Asia Studies, 53(6), 885-901.

Teitelbaum, S. and Beckley, T. (2006) Harvested, hunted and home grown: the prevalence of slefprovisioning in rural Canada. Journal of Rural Community Development, 1, 114-130. 
Tornaghi, C. (2017) Urban Agriculture in the Food-Disabling City: (Re)defining Urban Food Justice, Reimagining a Politics of Empowerment. Antipode 49 (3), 781-801.

Tregear, A. (2011) Progressing knowledge in alternative and local food networks: critical reflections and research agenda. Journal of Rural Studies 27 (4) 419-430.

Vávra, J., Daněk, P. and Jehlička, P. (2018) What is the contribution of food self-provisioning towards environmental sustainability? A case study of active gardeners. Journal of Cleaner Production 185, 1015-1023.

Veen, E. J., Derkzen, P. and Visser, A. J. (2014) Shopping Versus Growing: Food Acquisition Habits of Dutch Urban Gardeners. Food and Foodways, 22 (4), 268-299, DOI: 10.1080/07409710.2014.964604

Vidale, E., et al. (2016). 3.3. Trends, rural impacts and future developments of regional WFP market. StarTree Multipurpose trees and non-wood forest products a challenge and opportunity.

Visser, O. (2006) Property, labour relations and social obligations in Russia's privatised farm enterprises. In K. F. von Benda-Beckmann and M. Wiber (eds.) The Changing Properties of Property. London, New York: Berghahn, 205-234.

Visser, O. (2010) Insecure Land Rights, Obstacles to Family Farming and the Weakness of Protest in Rural Russia, Laboratorium, 2(2), 275-295.

Visser, O., Mamonova N., Spoor M. and Nikulin, A. (2015) 'Quiet Food Sovereignty' as Food Sovereignty without a Movement? Insights from Post-socialist Russia. Globalizations, 12(4), 513528.

Visser, O.; Dorondel, S. ;Jehlička, P.; Spoor, M. (2019a), Post-socialist smallholders: Silence, resistance and alternatives, Canadian Journal of Development Studies, 40(4), 499-510.

Visser, O.; Kurakin, A.; Nikulin, A. (2019b), Corporate Social Responsibility, Co-existence and Contention: Large farms' changing responsibility towards rural households in post-Soviet Russia, Canadian Journal of Development Studies, 40(4), 580-599.

Wädekin, K-E. (ed.) (1967) Privatproduzenten in der Sowjetischen landwirtschaft. Köln: Verlag Wissenschaft und Politik.

Wegren, S. K. (2018) The "left behind": Smallholders in contemporary Russian agriculture. Journal of Agrarian Change, 18, 913-925.

Wessely, A. and Csepeli Gy. (1996) The Cognitive Chance of Central European Sociology. In Hadas, M. and M. Vörös (eds.) Colonization or Partnership? Eastern Europe and Western Social Sciences. Replika

Special Issue. Budapest: Replika kör. 11-19. URL: http://www.c3.hu/scripta/scripta0/replika/honlap/english/01/01cwess.htm

Whatmore, S. (1995) From farming to agribusiness: the global agrofood system. In: Johnston, R., Taylor, P., Watts, M. (Eds.), Geographies of Global Change: Remapping the World in the Late Twentieth Century. Blackwell, Oxford.

Zavisca, J. (2003) Contesting Capitalism at the Post-Soviet Dacha: The Meaning of Food Cultivation for Urban Russians. Slavic Review, 62 (4), 786-810 


\begin{abstract}
${ }^{1}$ When comparing 'the West' with Eastern Europe, we include both North America and Western Europe. However, we focus more on Western Europe, as it has been the main reference point in assessing Eastern Europe's agro-food practices in academic, policy (the EU's CAP and other policies) and civil-society (for example, CSAs and NGOs operating in the sphere of food justice) discussions.

${ }^{2}$ The term 'global East' refers to the European part of the former 'Second World', that is, countries of the former Soviet Union and former socialist countries in Eastern Europe as an 'epistemic' and a 'liminal space in-between North and South' (Müller 2018).

${ }^{3}$ Getting published is a very different thing to having influence on and shaping international academic debates.
\end{abstract}

${ }^{4}$ As counter-examples, we also looked at citing articles of several articles on informal food practices that were researched by Western authors in Western contexts and published in international journals: Leake et al's (2009) article on grow-your-own in the UK. Thirty-four articles (out of the total 42) citing Leake et al. that could be attributed to specific countries were by authors researching countries from all over the world including nine West Europen countries, Poland, USA, Canada, Cuba, China, Brazil, Iraq and Morocco.

${ }^{5}$ We acknowledge that we have previously individually published several articles on East European agro-food alternatives. It needs to be stressed that these limited attempts at 'theory building from the East' are a very recent work. Most of us would admit that up until 2015 their work was about application of Western theories to East European contexts. Our earliest attempts to promote Eastern Europe as a source of theoretical insights date to the first half of the 2010s, but they received (a limited) attention in international academic communications in terms of citations only in the most recent several years (2018 and 2019). We are not aware of any previous collective effort similar to this paper to champion Eastern Europe as a source of theory building in agri-food studies.

${ }^{6}$ For the purposes of this study, searches in the Scopus database were conducted focusing on the terms 'alternative food networks', 'local food', 'small-scale farming', 'multi-functional agriculture' and 'food sharing'. In each case only articles published after 2000 (inclusive) were considered. The search inquiry was then modified to return separate tables showing the number of publications published by individual researchers, publications per institute, and publications per country.

${ }^{7}$ The CORDIS Europe homepage was used to identify EU funded projects addressing AFN or similar concepts. To give some examples, one or several East European countries have been participating in DIVERSIFOOD, SavingFood, FOODINTEGRITY, TRANSMANGO, GLAMUR, and PEGASUS food-related projects.

${ }^{8}$ The research by Soviet academics influenced policy, as evidenced by the gradually relaxed restrictions on household plots in the Soviet Union in the 1960s. Towards the end of his reign, Khrushchev reintroduced limits on some of the freedoms he had earlier granted to the household plots, as they remained anathema to communism. However, in some CEE countries such as Hungary and later Bulgaria (Hann, 2003), more freedom remained for household plots.

${ }^{9} \mathrm{~A}$ minor segment of the legal category of 'private/family farmers' are indeed of a small size and could in fact be classified as smallholder. The absolute number in this category is low, however, so it would not significantly change the overall tendencies as observed based on household plots.

${ }^{10}$ Although there is no quantitative comparative data substantiating these claims, it is possible to use evidence gathered in pan-European projects (such as EU FP7 project StarTree or Cost Action FP1203 NWFP) as an illustration of the differences described in the paper.

${ }^{11}$ As illustrated by Pouta et al. (2006) and Passilta et al. (2009), wild products play a similar role in Nordic countries as well.

${ }^{12}$ Unlike, for example, Finland, where commercial berry pickers are often brought from Thailand.

${ }^{13}$ International sanctions imposed on Russia in 2014 following its military intervention in Ukraine can be seen as an example of externally induced shocks to which Russia and for other reasons many other East European countries have been exposed since the early 1990s and to which the agro-food sector (both commercial and informal) displayed a remarkable degree of resilience. Sanctions are believed to have stimulated import substitution by large farms, as a result of which their share of food production slightly increased in relation to smallholders.

${ }^{14}$ Although outside the scope of this article, perhaps even beyond the West in general to the Global South. 